Tropical Journal of Pharmaceutical Research July 2019; 18 (7): 1405-1412

ISSN: $1596-5996$ (print); 1596-9827 (electronic)

(C) Pharmacotherapy Group, Faculty of Pharmacy, University of Benin, Benin City, 300001 Nigeria.

\title{
Curcumin inhibits epithelial-mesenchymal transition in colorectal cancer cells by regulating miR-206/SNAl2 pathway
}

\author{
Pan Zhao ${ }^{1}$, Chunjie Zhang ${ }^{2 \star}$, Dafei Xie ${ }^{2}$, Maowei Pei ${ }^{2}$ \\ ${ }^{1}$ Department of Pathology, Affiliated Hangzhou First People's Hospital, Zhejiang University School of Medicine, Hangzhou City \\ 310006, ${ }^{2}$ Department of General Surgery, Zhejiang Hospital, Hangzhou City, Zhejiang Province 310000, China
}

*For correspondence: Email: ChunjieZhang46@163.com; Tel: 0086-571-87377421; Fax: 0086-571-87377421

\begin{abstract}
Purpose: To examine the effects of curcumin on epithelial-mesenchymal transition (EMT) via regulation of miR-206 and SNAI2 in colorectal cancer (CRC) cells. Relationship between SNAI2 and miR-206 and the effects of curcumin on related mechanisms were also identified.

Methods: Transwell assays were used to analyze cellular migration and invasion. Genes associated with changes in protein and mRNA expression were evaluated by western blotting and quantitative reverse transcription PCR analyses, respectively. The relationship between SNAI2 and miR-206 was determined using a dual luciferase assay.

Results: Curcumin inhibited cell metastasis, upregulated miR-206 expression, and decreased SNAI2 levels. Furthermore, miR-206 directly targeted SNAI2 and inhibited EMT via downregulation of SNAI2 expression. Curcumin inhibited EMT in CRC cells by upregulating miR-206.

Conclusion: This study, for the first time, discovered the role of curcumin on epithelial-mesenchymal transition process in colorectal cancer cells by modulating miR-206/SNAI2 axis. These findings suggest that curcumin may be useful as a novel therapeutic agent to inhibit the metastasis of CRC.
\end{abstract}

Keywords: Epithelial-mesenchymal transition, Colorectal cancer, MiR-206, SNAI2, Cell migration, Curcumin

\begin{abstract}
This is an Open Access article that uses a fund-ing model which does not charge readers or their institutions for access and distributed under the terms of the Creative Commons Attribution License (http://creativecommons.org/licenses/by/4.0) and the Budapest Open Access Initiative (http://www.budapestopenaccessinitiative.org/read), which permit unrestricted use, distribution, and reproduction in any medium, provided the original work is properly credited.

Tropical Journal of Pharmaceutical Research is indexed by Science Citation Index (SciSearch), Scopus, International Pharmaceutical Abstract, Chemical Abstracts, Embase, Index Copernicus, EBSCO, African Index Medicus, JournalSeek, Journal Citation Reports/Science Edition, Directory of Open Access Journals (DOAJ), African Journal Online, Bioline International, Open-J-Gate and Pharmacy Abstracts
\end{abstract}

\section{INTRODUCTION}

Improper lifestyle and diet are the main risk factors for colorectal cancer (CRC) [1-3]. Despite advances in the study of CRC, it is still a common gastrointestinal malignancy with high mortality due to metastasis. Currently, the main challenge is the development of a clinically effective method to inhibit CRC metastasis. Metastasis is a complex process that is caused by multiple gene interactions. However, little is known about the exact mechanism by which CRC metastasis occurs.

Curcumin has been widely studied in a variety of tumors as a potential chemotherapy agent [4]. It can inhibit cancer cell invasion, proliferation, inflammation, and angiogenesis, promote apoptosis, and increase the sensitivity of tumors to chemotherapeutic drugs [5-7]. Curcumin also 
exert anticancer effects by regulating downstream genes or pathways via alterations in miRNA levels $[8,9]$. Bisphenol A-induced MCF-7 cell proliferation was found to be inhibited by the regulation of the miR-19/AKT/PTEN/p53 pathway [10]. The upregulation of miR-192-5p suppresses proliferation and promotes apoptosis in non-small cell lung cancer through preventing the PI3K/Akt pathway [11]. In CRC, curcumin inhibits cell invasion and migration by the regulation of the miR-21, miR-34a, and miR-27a expression. Moreover, via the regulation of miR-491 expression, curcumin was shown to inhibit the proliferation of HCT-116 cells and promote apoptosis [12]. However, in view of the complex pathogenesis of CRC, curcumin's mechanism of action requires further study.

Curcumin can upregulate miR-206 expression and decrease insulin signaling in fructoseinduced podocytes [13], but few studies have investigated the relation of miR-206 expression as well as curcumin in cancer. miR-206 plays a role in tumor suppression in multiple tumors, especially in $\mathrm{CRC}$, and has been shown to downregulate NOTCH3 and inhibit tumor proliferation and metastasis [14]. miR-206 can also inhibit CRC progression by targeting FMNL2 [15] and can increase 5-fluorouracil (5-FU) sensitivity via the inhibition of $\mathrm{Bcl}-2$ expression [16]. However, in CRC, whether curcumin can regulate the miR-206 expression is unknown. This study investigated the role of curcumin on the epithelial-mesenchymal transition process in CRC cells, and discovered its function in regulating miR-206/SNAI2 axis.

\section{EXPERIMENTAL}

\section{Cell culture and reagents}

Sigma-Aldrich (St. Louis, MO, USA) provided the curcumin (99\% purity). American Type Culture Collection (CCL-247, USA) provided HCT116
CRC cell. Cells were incubated in DMEM (Gibco, USA) containing 10\% FBS (Gibco) and $100 \mathrm{U} / \mathrm{mL}$ penicillin-streptomycin (Gibco), and maintained in an incubator: humidified, $37^{\circ} \mathrm{C}, 5 \% \mathrm{CO}_{2}$.

\section{HCT116 cell transfection}

GenePharma (Shanghai, China) synthesized miR-206 mimics, miR-206 inhibitor, SNAI2 plasmid, respective negative controls. Table 1 shows the primers sequences. According to the manufacturer's instructions, the miR-206 mimics (50 nM), miR-206 inhibitor (50 nM), SNAI2 plasmid (50 nM), and respective negative controls were transfected into differentiated podocytes by Lipofectamine 2000 (Invitrogen, Carlsbad, CA, USA). After 2 days of growth, the original medium was discarded, and RPMI-1640 culture medium (Gibco, USA) was selected to the transfected cells.

\section{Transwell assay}

HCT116 cells $\left(1-2 \times 10^{5}\right)$ were seeded into the top chambers (pore size of $8-\mu \mathrm{m}$ ) of Transwell plates (Costar, UK). After $12 \mathrm{~h}$, cells from at least six fields of view were photographed under a microscope and counted for the migration assay. The same number of HCT116 cells were also seeded into top chambers precoated with Matrigel (BD Biosciences, USA) and incubated for one day for the invasion assay.

\section{qRT-PCR}

The total cells RNA was extracted by Trizol reagent (Invitrogen, Carlsbad, CA) and the SuperScript RT kit from Invitrogen (Invitrogen, Carlsbad, CA) was used to reverse-transcribed. Using the PowerUp ${ }^{\mathrm{TM}}$ SYBR $^{\circledR}$ Green Master Mix (Thermo Fisher Scientific, USA) and the ABI PRISM7900 Sequence Detection System (Applied Biosystems, USA),

Table 1: Sequence of miRNA and mRNA primers

\begin{tabular}{|c|c|c|}
\hline Gene & Forward $\left(5^{\prime}-3^{\prime}\right)$ & Reverse (5'- 3') \\
\hline miR-206 & CAGA TCCGATTGGAATGTAAGG & TATGCT TGTTCTCGTCTCTGTGTC \\
\hline SNAI2 & ATGAGGAATCTGGCTGCTGT & CAGGAGAAAATGCCTTTGGA \\
\hline & GTAGTCGGCGAAGGTCTCAC & ACCGTGGATGCAATGCCTAA \\
\hline $\begin{array}{l}\text { miR-206 } \\
\text { mimics }\end{array}$ & UGGAAUGUAAGGAAGUGUGUGG & ACACACUUCCUUACAUUCCAUU \\
\hline Negative & UUCUCCGAACGUGUCACGUTT & ACGUGACACGUUCGGAGAATT \\
\hline $\begin{array}{l}\text { miR-206 } \\
\text { inhibitor }\end{array}$ & CCACACACUUCCUUACAUUCCA & \\
\hline $\begin{array}{l}\text { SNAI2 } \\
\text { plasmid }\end{array}$ & GGACTAGTATGCCGCGCTCCTTCCTGGTC & $\begin{array}{l}\text { CGGAATTCTCAGTGTGCTACACAG } \\
\text { CAGCCAGATTC }\end{array}$ \\
\hline GAPDH & AAGGAAATGAATGGGCAGCC & TAGGAAAAGCATCACCCGGA \\
\hline
\end{tabular}


qRT-PCR was subsequently performed using the primers shown in Table 1 . The $2^{-\Delta \Delta \mathrm{Ct}}$ method was used for miRNA and mRNA expression analyses [17]; glyceraldehyde 3-phosphate dehydrogenase (GAPDH) and U6 snRNAs served as the positive controls.

\section{Luciferase reporter assay}

The mutant (MUT) SNAI2 3'-untranslated region (UTR) and wild-type (WT) SNAI2 3'-UTR, which both contained a putative binding site of miR206, were synthesized and inserted into the reporter vector of pmirGLO dual luciferase (YouBio, Changsha, China). Reporter vectors containing the MUT and WT SNAI2 3'-UTRs, and the NC-mimic/miR-206 mimic, were cotransfected into HEK293T cells and cultured until the cells reached $45 \%$ confluence. After $48 \mathrm{~h}$, the assay of dual luciferase system (Promega, Madison, USA) was used to evaluate the levels of luciferase, which were normalized to those of the Renilla luciferase.

\section{Western blot}

HCT116 cells were homogenized on ice for half an hour in RIPA buffer (Sigma-Aldrich, USA) with protease inhibitors. The homogenate was then centrifuged, 12,000 rpm, $15 \mathrm{~min}$; and collected the supernatant and stored at $-20{ }^{\circ} \mathrm{C}$. Electrophoresis on $12 \%$ sodium dodecyl sulfatepolyacrylamide gels using Tris-glycine running buffer was performed to separate total proteins, which were then immobilized onto PVDM (Sigma-Aldrich, USA). Nonspecific binding was blocked by gentle shaking in Tris-buffered saline with $3 \%$ bovine serum albumin and $0.1 \%$ Tween-20 for one hour at room temperature. Then the membranes were cultured with the following primary antibodies: anti-Zeb1 (1:1000, Applygen), anti-SNAI2 (1:1000, Santa Cruz, USA), anti-E-cadherin (1:1000, Abcam, USA), anti-Vimentin (1:1000, Applygen, Beijing, China), anti-Snail (1:1000, Abcam), and anti-GAPDH (1:1000, Applygen) overnight at $4{ }^{\circ} \mathrm{C}$. Proteins were visualized using a LAS-4000 mini system (Fujifilm, Japan) and quantified using Quantity one software. Protein expression levels were standardized to those of GAPDH.

\section{Statistical analysis}

GraphPad 8.0 software was used to analyze the data. Results are presented as mean \pm standard deviation (SD) and all experiments were repeated three times. $P<0.05$, was considered statistically significant, ANOVA was performed to determine the significance of differences among experimental groups.

\section{RESULTS}

\section{Curcumin inhibits cell metastasis, upregulates miR-206 expression, and decreases SNAI2 levels}

The effects of graded concentrations $(0-30$ $\mu \mathrm{mol} / \mathrm{L})$ of curcumin on the HCT116 cells migration and invasion were investigated. The results showed that both invasion and migration were suppressed by curcumin (Figure $1 \mathrm{~A}$ and B). Increased concentrations of curcumin led to significant changes in the inhibitory efficacy(all $p$ $<0.05)$. A biological analysis was used to determine whether curcumin had any effects on miR-206 and SNAI2. HCT116 cells were treatment of different concentrations of curcumin for one day, the miR-206 mRNA expression and SNAI2 protein levels were evaluated by qRTPCR and western blotting. The miR-206 mRNA levels were markedly increased (Figure 1C) and the protein levels of SNAI2 were decreased in HCT116 cells treated with curcumin (Figure 1D). These results suggest that curcumin suppresses cell metastasis, upregulates miR-206 expression, and decreases SNAI2 levels.

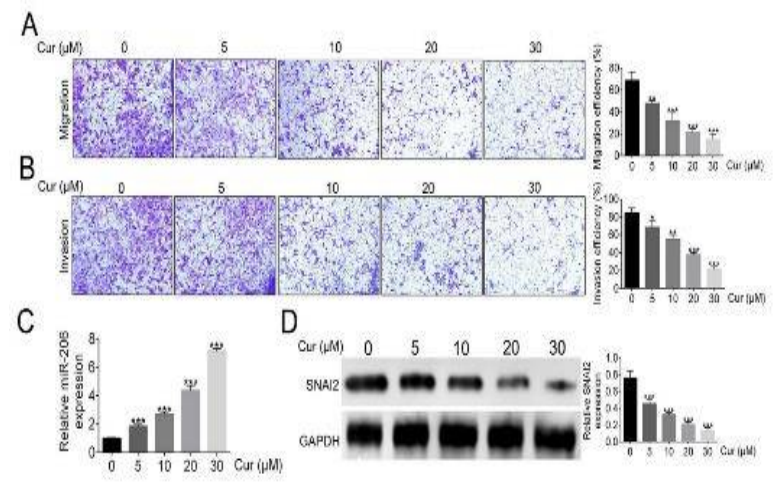

Figure 1: The effects of Curcumin on the migration, invasion and the expression of miR-206 and SNAI2 in HCT116 cells. (A) Migration and (B) invasion of HCT116 cells after curcumin treatment $(0,5,10,20$, and $30 \mu \mathrm{M}$ ) for $24 \mathrm{~h}$ observed by the Transwell assay. (C) The mRNA expression levels of miR-206 in HCT116 cells after curcumin $(0,5,10,20$, and 30 $\mu \mathrm{mol} / \mathrm{L})$ treated for $24 \mathrm{~h}$ were measured using qRTPCR. (D) The protein expression levels of SNAI2 in HCT116 cells after curcumin $(0,5,10,20$, and 30 $\mu \mathrm{mol} / \mathrm{L})$ treated for $24 \mathrm{~h}$ were evaluated by western blotting; ${ }^{*} p<0.05,{ }^{* *} p<0.01,{ }^{* * *} p<0.001$ vs. HCT116 cells treated with curcumin $(0 \mu \mathrm{mol} / \mathrm{L})$, respectively

\section{MiR-206 binds SNAI2 and inhibit SNAI2 expression}

SNAI2, as a target of miR-206, was indicated to contain an miR-206-binding site in the TargetScan database. To verify this prediction, both MUT and WT SNAI2 3'UTRs were cloned 
into the reporter system (Figure $2 \mathrm{~A}$ ). To validate whether SNAI2 expression could be directly regulated by miR-206, SNAI2 protein levels in HCT116 cells that were overexpressing miR-206 by western blot analysis were examined. Figure 2 B shows that SNAI2 levels were reduced in these cells. In addition, Figure $2 \mathrm{C}$ shows that WT SNAI2 3'-UTR luciferase activity was inhibited when miR-206 mimics were cotransfected with the vector $(p<0.001)$, whereas MUT SNAI2 3'-UTR luciferase activity was not significantly affected by co-transfection of miR206 mimics. These data suggest that miR-206 can directly target SNAI2 and suppress SNAI2 expression levels in HCT116 cells.
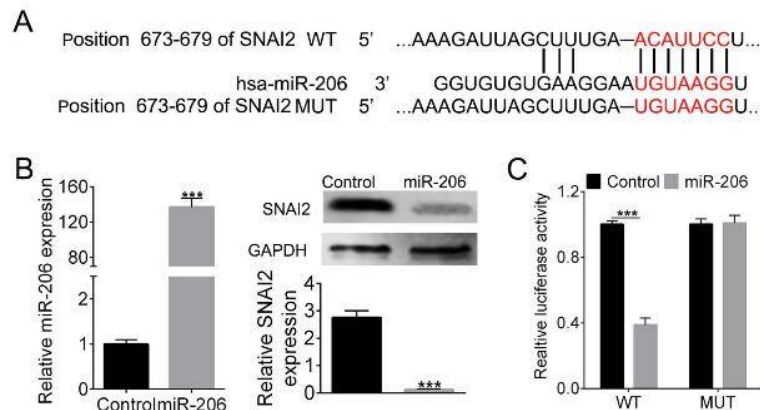

Figure 2: MiR-206 binds SNAI2 and inhibits SNAI2 expression. (A) A binding site of miR-206 in the 3'UTR of SNAI2 was identified by TargetScan. (B) The levels of miR-206 mRNA in HCT116 cells overexpressing miR-206 and SNAI2 expression levels in HCT116 cells transfection of miR-206 mimics were evaluated by QRT-PCR and western blotting, respectively. (C) The MUT and WT SNAI2 3'-UTR luciferase activities constructs were measured in HCT116 cells transfection of miR-206 mimics; ${ }^{* * *} p<$ 0.001 vs. control

\section{MicroRNA-206 inhibits EMT in HCT116 cells via downregulating SNAIL2}

Next, this study overexpressed SNAI2 in HCT116 cells. Western blot and qRT-PCR results showed a successful overexpression $(p<$ 0.001 , Figure $3 \mathrm{~A}$ ). To further determine the mechanism by which miR-206 affects CRC progression, levels of proteins associated with the EMT were measured. As shown in Figure 3 B, miR-206 overexpression markedly increased E-cadherin levels, whereas in HCT116 cells, SNAI2, vimentin, Zeb1, and Snail levels were reduced as compare to the control + NC group. While a significant reduce in E-cadherin protein level and increases in SNAI2, Vimentin, Zeb1, and Snail protein levels were found in HCT116 cells transfection of SNAI2 and miR-206 mimics. Moreover, results in Figure $3 \mathrm{C}$ showed that both the migration and invasion of HCT116 cells were blocked through miR-206 mimics $(p<0.001)$, whereas the number of cells undergoing invasion and migration were dramatically increased after transfection of miR-206 mimic + SNAI2 $(P<$ $0.001)$. These data suggest that miR-206 blocks $\mathrm{CRC}$ progression via the regulation of proteins associated with EMT.
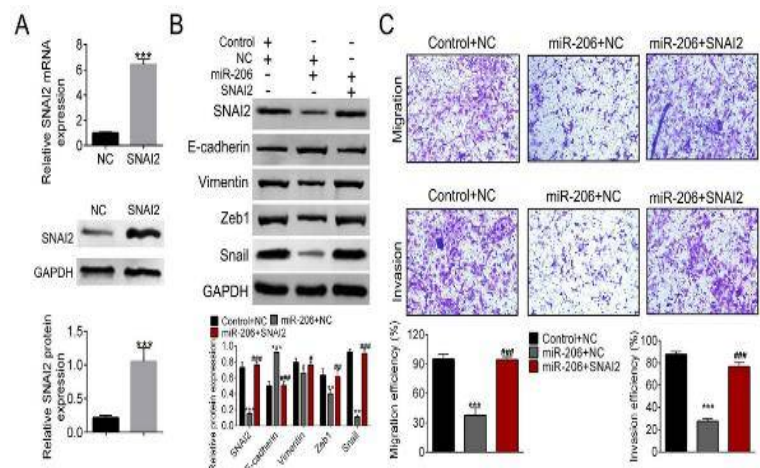

Figure 3: The EMT is inhibited via the downregulation of SNAI2 expression by miR-206. (A) Overexpression of SNAI2 in HCT116 cells was evaluated by qRT-PCR and western blotting. (B) SNAI2, E-cadherin, Zeb1, Vimentin, and Snail protein expression in HCT116 cells was evaluated by western blotting after transfection of miR-206 + NC, miR-206 mimics or miR206 + SNAl2. (C) HCT116 cells invasion and migration were evaluated using the Transwell assay after transfection of miR-206 + NC, miR-206 mimics or miR$206+$ SNAI2; ${ }^{*} p<0.05,{ }^{* *} p<0.01,{ }^{* * *} p<0.001$, compared with Control + NC group. ${ }^{\#} p<0.05$, \# $p<$ $0.01,{ }^{\# \# \#} p<0.001$, compared with miR-206 + SNAI2 group

\section{Curcumin inhibits EMT of CRC cells upregulated miR-206}

The results of qRT-PCR expressed that the miR206 knockdown in HCT116 cells caused a reduction in the mRNA expression of miR-206 levels $(p<0.001$, Figure 4 A). miR-206 overexpression was observed in HCT116 cells after treatment with curcumin compared with control $(p<0.001)$. In addition, we found a marked reduction in miR-206 expression levels in HCT116 cells after miR-206 knockdown in combination with curcumin compared with treatment with curcumin alone $(p<0.001)$. However, expression of miR-206 levels were increased in HCT116 cells after miR-206 knockdown and treatment with curcumin compared to miR-206 knockdown alone $(p<$ 0.001 ), as shown in Figure $4 \mathrm{~B}$. Furthermore, after treatment with curcumin, E-cadherin protein levels were markedly increased, and SNAI2, Vimentin, Zeb1, and Snail protein expression levels were decreased in HCT116 cells. However, knockdown of miR-206 had the opposite effect on the levels of these proteins.

Compared to miR-206 knockdown alone, the levels of E-cadherin were reduced and the 
SNAI2, Vimentin, Zeb1, and Snail levels were increased in HCT116 cells by knockdown of miR206 and treatment with curcumin (Figure $4 \mathrm{C}$ ). The invasion and migration of HCT116 cells after treatment with curcumin or miR-206 knockdown were further analyzed in this study (Figure 4D). After treatment with curcumin, the number of cells undergoing migration and invasion was dramatically decreased (all $p<0.01$ ), whereas treatment with curcumin or knockdown of miR206 markedly improved the number of HCT116 undergoing migration and invasion. Intriguingly, after knockdown of miR-206 and treatment with curcumin, cellular migration and invasion were inhibited in HCT116 cells. These data demonstrate that curcumin inhibits the EMT in $\mathrm{CRC}$ cells via upregulating miR-206.

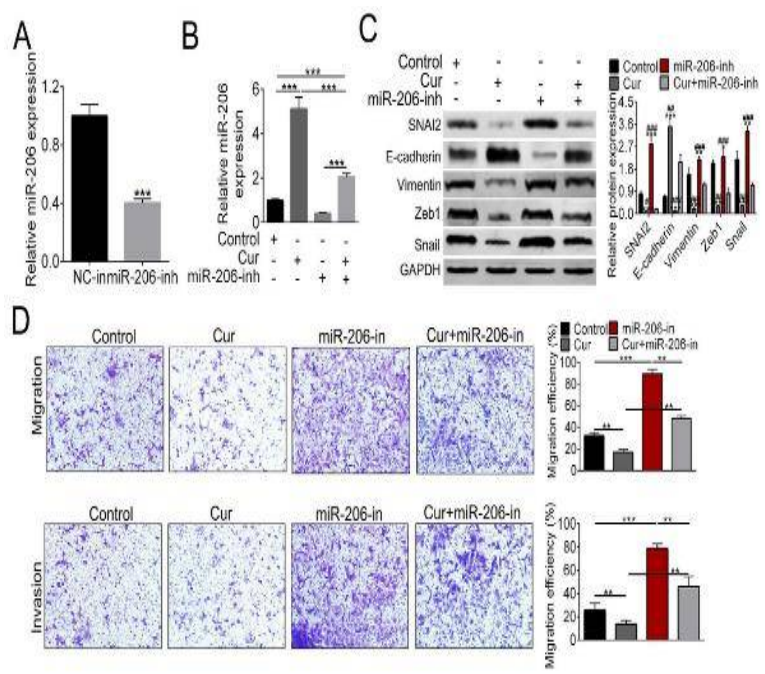

Figure 4: The effect of Curcumin on CRC cell EMT. Expression of miR-206 mRNA in HCT116 cells was evaluated by qRT-PCR after knockdown of miR-206 (A) and after treatment with curcumin $(20 \mu \mathrm{mol} / \mathrm{L})$, knockdown of miR-206, or both (B). (C) Western blot analyses of SNAI2, E-cadherin, Zeb1, Vimentin, and Snail expression in HCT116 cells after treatment with curcumin $(20 \mu \mathrm{mol} / \mathrm{L})$, knockdown of miR-206, or both. (D) HCT116 cells migration and invasion was observed using the Transwell assay after treatment with curcumin $(20 \mu \mathrm{mol} / \mathrm{L})$, knockdown of miR-206, or both; ${ }^{\star} p<0.05,{ }^{\star *} p<0.01,{ }^{* * *} p<0.001,{ }^{\#} p<0.05,{ }^{* \#} p$ $<0.01,{ }^{\# \#} p<0.001$, statistically significant

\section{DISCUSSION}

In the present experiment, treatment of CRC HCT116 cells with curcumin inhibited cell metastasis, upregulated miR-206 expression, and decreased SNAI2 levels. miR-206 was shown to bind SNAI2 and inhibit SNAI2 expression. Furthermore, miR-206 inhibited the EMT by downregulating SNAI2 expression. After treatment with curcumin, the EMT of HCT116 cells was inhibited and the expression of miR206 was upregulated. These results suggest that curcumin inhibits the EMT by regulating the miR206/SNAI2 pathway in CRC cells.

Colorectal cancer is considered the 3rd-most usual type of tumor worldwide the development and progression of CRC are known to involve several genetic and environmental risk factors including chromosomal abnormalities, epigenetic changes, and unhealthy lifestyles. Various biomarkers, such as RNAs, DNAs, epigenetic changes, glycoproteins and proteins, and microRNAs, have been investigated for the prognosis, diagnosis, and treated with CRC patients. Previous reports have suggested that miR-206 can regulate different target genes that function in various cell processes, for example, cell differentiation, apoptosis and proliferation [18-20]. As a unique transcription factor for androgens, SNAI2 coordinates androgen receptors and promotes resistance to prostate cancer [21]. Curcumin has been reported to inhibit the activation of carcinogens and elicit anti-metastatic and anti-invasive effects in breast, lung, and prostate cancers [22,23]. In the present study, HCT116 cells were treatment of graded concentrations of curcumin, resulting in the strong inhibition of cellular migration and invasion. Additionally, the study firstly report that curcumin upregulates miR-206 expression and downregulates SNAI2 expression.

SNAI2 belongs to the Snail superfamily and is a highly conserved zinc finger transcription factor participated in both normal development and carcinogenesis [24-26]. Therefore, it is of great importance to demonstrate the SNAI2-mediated regulation of cancer cell migration and invasion. Various miRNAs were found to be downregulated in many types of tumors and may mediate tumorigenesis by targeting tumor suppressor genes.[27] Prior work reported that decreased miR-206 expression levels were related to the clinical progression of CRC [28]. However, the roles and expression levels of miR206/SNAI2 in CRC have not been clearly reported until now. In our study, we used bioinformatics analyses and transfection assays to confirm that miR-206 exhibited a tumor suppressor effect via the downregulation of SNAI2. In our opinion, we firstly explore the posttranscriptional regulation of SNAI2 by miR-206 in CRC.

The EMT is involved in many stages of cancer progression. Tumor cells are endowed with more aggressive phenotypes during the EMT, such as stem cell-like and mesenchymal features [29]. This transition results in cellular migration and invasion. The EMT reduces the proteins expression that promote cell-cell contact, for 
example, a-catenin and E-cadherin, and increases the mesenchymal markers levels, including Vimentin, Zeb1, and Snail [30]. In the current experiment, we identified the role and mechanism of action of miR-206/SNAI2 in the suppression of the EMT in CRC. Snail family transcriptional repressor 2expression was downregulated and the EMT process was inhibited by miR-206 in CRC cell lines. As for the EMT markers, Vimentin, Zeb1, and Snail expression levels were reduced after transfection with miR206 mimics, whereas E-cadherin expression was markedly improved. The miR-206 overexpression was shown to inhibit invasion and migration of cell by down-regulation the SNAI2 expression.

Curcumin has been shown to suppress miR-21 transcription via AP-1, inhibit cancer migration and invasion in vivo, and stabilize the cancer suppressor PDCD4 in CRC [31]. Moreover, curcumin has been shown to inhibit metastasis via the regulation of miR-181b expression by targeting the down-regulation of CXCL1 and CXCL2 levels in breast cancer [32]. Curcumin has also been shown to inhibit metastasis via the up-regulation of miR-7 expression, as well as the down-regulation of SET8, in pancreatic cancer [8]. This study appears to be the first to confirm that the anti-metastatic roles of curcumin are related to the miR-206/SNAI2 pathway and the EMT in CRC. Curcumin was shown to strongly inhibit CRC via upregulating miR-206 expression, the suppression of both EMT and SNAI2 expression, and the inhibition of cancer cell invasion and migration.

\section{CONCLUSION}

The findings of this study show, for the first time, that curcumin serves as a suppressor of EMT in CRC cells by modulating miR-206/SNAI2 pathway. Hopefully, these results provide a new candidate target for the future development of therapeutic interventions against CRC metastasis.

\section{DECLARATIONS}

\section{Acknowledgement}

This work was funded by a project entitled, "Study on the correlation between key molecules of energy metabolism symbiosis (GLUT1 and MCT1/4) and clinical prognosis of colon cancer FOLFOX chemotherapy regimen" (grant no. 2018KY583).

\section{Conflict of interest}

No conflict of interest is associated with this work.

\section{Contribution of authors}

We declare that this work was performed by the authors of this article. All liabilities related with the content of this article will be borne by the authors. Pan Zhao and Chunjie Zhang designed all the experiments and revised the manuscript. Dafei Xie and Maowei Pei formed the experiments, and Pan Zhao wrote the paper.

\section{Open Access}

This is an Open Access article that uses a funding model which does not charge readers or their institutions for access and distributed under the terms of the Creative Commons Attribution License (http://creativecommons.org/licenses/by/ 4.0) and the Budapest Open Access Initiative (http://www.budapestopenaccessinitiative.org/rea d), which permit unrestricted use, distribution, and reproduction in any medium, provided the original work is properly credited.

\section{REFERENCES}

1. Colleen P, Hannah A, Pfeiffer RM, Elena JW, Alfano CM, Hollenbeck AR, Yikyung $P$. Prediagnostic lifestyle factors and survival after colon and rectal cancer diagnosis in the National Institutes of Health (NIH)AARP Diet and Health Study. Cancer 2014; 120(10): 1540-1547.

2. Faiza N, Martin RS, Pawel G, Jakub P, Stefan W, Patric $U$, Jaroslaw $R$, Primo SR, Kaspar T. Modulation of ageand cancer-associated DNA methylation change in the healthy colon by aspirin and lifestyle. J Natl Cancer Inst 2014; 106(7): 766-776.

3. Winkels RM, Heine-Bröring RC, Zutphen MV, HartenGerritsen SV, Kok DE, Duijnhoven FJV, Kampman E. The COLON study: Colorectal cancer: Longitudinal, Observational study on Nutritional and lifestyle factors that may influence colorectal tumour recurrence, survival and quality of life. BMC Cancer 2014; 14(1): 18.

4. Shanmugam $M$, Rane $G$, Kanchi $M$, Arfuso $F$, Chinnathambi A, Zayed M, Alharbi S, Tan B, Kumar A, Sethi $G$. The multifaceted role of curcumin in cancer prevention and treatment. Molecules 2015; 20(2): 27282769.

5. Bar SG, Epelbaum RM. Curcumin as an anti-cancer agent: review of the gap between basic and clinical applications. Curr Med Chem 2010; 17(3): 190-197.

6. Cao $F$, Liu $T, X u Y, X u D$, Feng $S$. Curcumin inhibits cell proliferation and promotes apoptosis in human 
osteoclastoma cell through MMP-9, NF-KB and JNK signaling pathways. Int J Clin Exp Pathol 2015; 8(6): 6037-6045.

7. Seyung SC, Jaydutt VV. Curcumin and epigallocatechin gallate inhibit the cancer stem cell phenotype via downregulation of STAT3-NFKB signaling. Anticancer Res 2015; 35(1): 39-46.

8. Ma J, Fang B, Zeng $F$, Pang $H$, Zhang J, Shi $Y, W u X$, Cheng L, Ma C, Xia J. Curcumin inhibits cell growth and invasion through up-regulation of miR-7 in pancreatic cancer cells. Toxicol Lett 2014; 231(1): 82-91.

9. Momtazi AA, Shahabipour $F$, Khatibi $S$, Johnston TP, Pirro M, Sahebkar A. Curcumin as a MicroRNA Regulator in Cancer: A Review. Rev Physiol Biochem Pharmacol 2016; 171: 1-38.

10. Xiaoting L, Wei $X$, Chunfeng $X$, Cong $H$, Jianyun $Z$, Zhaofeng L, Feifei $D$, Mingming $Z$, Weiwei $Z$, Rui $W$. Curcumin modulates miR-19/PTEN/AKT/p53 axis to suppress bisphenol A-induced MCF-7 breast cancer cell proliferation. Phytother Res 2015; 28(10): 1553-1560.

11. Jin H, Qiao F, Wang $Y, X u Y$, Shang $Y$. Curcumin inhibits cell proliferation and induces apoptosis of human nonsmall cell lung cancer cells through the upregulation of miR-192-5p and suppression of PI3K/Akt signaling pathway. Oncol Rep 2015; 34(5): 2782-2789.

12. Li B, Shi C, Li B, Zhao JM, Wang L. The Effects of Curcumin on HCT-116 Cells Proliferation and Apoptosis via the miR-491/PEG10 Pathway. J Cell Biochem 2017; 119(4): 3091-3098.

13. Ding $X Q$, Gu TT, Wang $W$, Song $L$, Chen $T Y, X u e Q C$, Zhou F, Li JM, Kong LD. Curcumin protects against fructose-induced podocyte insulin signaling impairment through upregulation of miR-206. Mol Nutr Food Res 2016; 59(12): 2355-2370.

14. Xiao-Wei W, Xue-Qin X, Jian W, Yi-Yuan W, Hong-Xia H, Xiu-Feng C. MicroRNA-206 attenuates tumor proliferation and migration involving the downregulation of NOTCH3 in colorectal cancer. Oncol Rep 2015; 33(3): 1402-1410.

15. Ren XL, He GY, Li XM, Men H, Yi LZ, Lu GF, Xin SN, Wu PX, Li YL, Liao WT. MicroRNA-206 functions as a tumor suppressor in colorectal cancer by targeting FMNL2. J Cancer Res Clin Oncol 2015; 142(3): 581-592.

16. Meng X, Fu R. MiR-206 regulates 5-FU resistance by targeting Bcl-2 in colon cancer cells. Onco Targets Ther 2018; 11: 1757-1765.

17. Livak KJ, Schmittgen TD. Analysis of relative gene expression data using real-time quantitative $P C R$ and the 2- $\triangle \triangle C T$ method. Methods 2001; 25(4): 402-408.

18. Liu F, Zhao X, Qian Y, Zhang J, Zhang Y, Yin R. MiR-206 inhibits Head and neck squamous cell carcinoma cell progression by targeting HDAC6 via PTEN/AKT/mTOR pathway. Biomed Pharmacother 2017; 96: 229-237.

19. Pan JY, Sun CC, Bi ZY, Chen ZL, Li SJ, Li QQ, Wang YX, Bi YY, Li DJ. miR-206/133b Cluster: A Weapon against Lung Cancer? Mol Ther Nucleic Acids 2017; 8 : 442-449.
20. Pang C, Huang G, Luo K, Dong Y, He F, Du G, Xiao M, Cai W. miR-206 inhibits the growth of hepatocellular carcinoma cells via targeting CDK9. Cancer Med 2017; 6(10): 2398-2409.

21. Wu K, Gore C, Yang L, Fazli L, Gleave M, Pong RC, Xiao $G$, Zhang L, Yun EJ, Tseng SF. Slug, a unique androgen-regulated transcription factor, coordinates androgen receptor to facilitate castration resistance in prostate cancer. Mol Endocrinol 2012; 26(9): 14961507.

22. Chen $Q Y$, Jiao DM, Wang LF, Wang L, Hu HZ, Song J, Yan J, Wu LJ, Shi JG. Curcumin inhibits proliferationmigration of NSCLC by steering crosstalk between a Wnt signaling pathway and an adherens junction via EGR-1. Mol Biosyst 2015; 11(3): 859-868.

23. Jagtap $S$, Meganathan KV, Winkler J, Hescheler J, Sachinidis A. Chemoprotective mechanism of the natural compounds, epigallocatechin-3-o-gallate, quercetin and curcumin against cancer and cardiovascular diseases. Curr Med Chem 2009; 16(12): 1451-1462.

24. Baygi ME, Soheili ZS, Essmann F, Deezagi A, Engers R, Goering W, Schulz WA. Slug/SNAI2 regulates cell proliferation and invasiveness of metastatic prostate cancer cell lines. Tumour Biol 2010; 31(4): 297-307.

25. Little GH, Baniwal SK, Helty A, Susan G, Nyam-Osor C, Young KS, Omar K, Debra $H$, Jones JO, Jacek $P$. Differential effects of RUNX2 on the androgen receptor in prostate cancer: synergistic stimulation of a gene set exemplified by SNAI2 and subsequent invasiveness. Cancer Res 2014; 74(10): 2857-2568.

26. Silvia E, Russo MV, Irma A, Maria Grazia T, Carlo S, Giulia B, Serena DM, Emma DC. SNAI2/Slug gene is silenced in prostate cancer and regulates neuroendocrine differentiation, metastasis-suppressor and pluripotency gene expression. Oncotarget 2015; 6(19): 17121-17134.

27. Lin SJ, Chou FJ, Li L, Lin CY, Yeh S, Chang C. Natural killer cells suppress enzalutamide resistance and cell invasion in the castration resistant prostate cancer via targeting the androgen receptor splicing variant 7 (ARv7). Cancer Lett 2017; 398: 62-69.

28. Li W, Chang J, Tong D, Peng J, Huang D, Guo W, Zhang $W$, Li J. Differential microRNA expression profiling in primary tumors and matched liver metastasis of patients with colorectal cancer. Oncotarget 2017; 8(22): 3578335791.

29. Karacosta LG, Anchang B, Kimmey S, van de Rijn $M$, Shrager JB, Bendall SC, Plevritis SK: Identifying dynamic EMT states and constructing a proteomic EMT landscape of lung cancer using single cell multidimensional analysis. In.: AACR; 2018.

30. Thiery JP, Sleeman JP. Complex networks orchestrate epithelial-mesenchymal transitions. Nat Rev Mol Cell Biol 2006; 7(2): 131-142.

31. Mudduluru G, George-William JN, Muppala S, Asangani $I A$, Kumarswamy $R$, Nelson LD, Allgayer $H$. Curcumin regulates miR-21 expression and inhibits invasion and 
Zhao et al

metastasis in colorectal cancer. Biosci Rep 2011; 31(3): 185-197.

32. Kronski E, Fiori ME, Barbieri O, Astigiano S, Mirisola V, Killian PH, Bruno A, Pagani A, Rovera $F$, Pfeffer $U$.
miR181b is induced by the chemopreventive polyphenol curcumin and inhibits breast cancer metastasis via down-regulation of the inflammatory cytokines CXCL1 and-2. Mol Oncol 2014; 8(3): 581-595. 